\title{
A fuzzy-PID controller in shell and tube heat exchanger simulation modeled for temperature control
}

\author{
C. Somasundar Reddy, K. Balaji
}

Departmentof EEE, St. Peter's Institute of Higher Education and Research, India

\begin{tabular}{|c|c|}
\hline Article Info & ABSTRACT \\
\hline Article history: & \multirow{9}{*}{$\begin{array}{l}\text { Shell and tube heat exchanger are the most generally utilized types of heat } \\
\text { exchanger for heat transfer in many industrial purposes. Shell and tube heat } \\
\text { exchanger comprise a set of units. One unit includes mechanical parts and } \\
\text { another unit consists of controlling part. Both the unit has to be modelled to } \\
\text { ensure the efficient operation of shell and tube heat exchanger. The } \\
\text { mechanical modelling is completely established on the type of applications. } \\
\text { The controller modelling is independent of the kind of applications. The } \\
\text { controller only needs the input fluid and output fluid properties such as } \\
\text { temperature and flow rate. Hence the primary objective of the paper is to } \\
\text { focus on the controller part for enhancing the heat exchanger performance. } \\
\text { This paper proposes the novel fuzzy-PID controlling technique based on the } \\
\text { multiplication operation to make the settling time and overshoot of setpoint } \\
\text { temperature to be less to a greater extent and the results are compared with } \\
\text { the conventional PI method with various tuning algorithms. }\end{array}$} \\
\hline Received Nov 11, 2019 & \\
\hline Revised Apr 9, 2020 & \\
\hline Accepted Jun 5, 2020 & \\
\hline Keywords: & \\
\hline Fuzzy-PID & \\
\hline Peak overshoot & \\
\hline Settling time & \\
\hline Shell andtube heat exchanger & \\
\hline
\end{tabular}

This is an open access article under the CC BY-SA license.

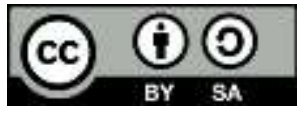

Corresponding Author:

C. Somasundar Reddy

Department of EEE, St. Peter's Institute of Higher Education and Research

Tonakela Camp Road, Sankar Nagar, Avadi, Chennai, Tamil Nadu 600054, India

Email: somasundarphd@gmail.com

\section{INTRODUCTION}

Generally, the shell and tube heat exchangers with optimal design and control techniques are used in many industrial applications such as chemical, food and refrigeration industries [1-5]. This exchanger consists of two structures one is shell and tube. The tube structure belongs to the input fluid or process fluid which is to be heated and shell structure belongs to the fluid which will transfer the heat to the input fluid. The tube structure consists of tubes and shell structure consists of a cylindrical shell [6-8]. The modeling of the controller is also a time overwhelming process. In order to model the controller first, there should be a complete understanding of heat exchanger process. The accurate modeling of the system is quite difficult to achieve is the drawback of the existing methods [9-11].

Hereafter, the nominal modeling should be based on both the open and closed loop conditions. The controller's main objective is to maintain the output process fluid temperature according to the set point. The controlling parameter includes a flow rate of fluid coming to the shell structure and it also takes the flow rate of input fluid as a disturbance. After the modeling, there is a decision-making step to choosing the control techniques. There are various control techniques are available in practice [12-15]. The typical PID controller has been attracted by many industries because of easy modeling, tuning of constants flexibility and controllability [16-19]. The constants are normally tuned by the Ziegler-Nichols method. This method gives the nominal values of tuning constants with quick response and acceptableness of changing conditions. In spite of its advantages, it also has disadvantages such as optimization of tuning constants and it can be honorably used for the linear systems rather than the non-linear systems due to its low performance on non- 
linear systems [20-21]. The fuzzy logic is introduced and it uses their expert systems of arranging the operating points which increases the accuracy [22-23]. The other controller such as SMC and MPC has high benefits over dynamic control but it is quite complex to design and hard to implement. Nowadays the combined structure of controllers has been designed. The main aim of the design is to utilize both the benefits of the combined controllers. The fuzzy-PID has attracted most of the researchers because of its simple structure as well as PID has the advantage of high performance on steady state and fuzzy has the advantage of high performance on the dynamic state [24-25]. Owing to their advantage fuzzy-PID has been used but there are various mathematical operations are performed between the outputs coming from them. The optimal operation has to be chosen for the desired plant operations.

In this paper, the mathematical model of the controller has been developed for the shell and tube heat exchanger using transfer functions. The objective is to build a detailed model of shell and tube heat exchanger in MATLAB/Simulink based on experimental data and exchangers mathematical model. Fuzzy and PID control schemes are used to control the temperature of outlet fluid from heat exchanger. This model is controlled in which flow rates and inlet temperature for hot stream is set and temperatures can be monitored simultaneously with measured flow rates. The modeling is based on the flow rate of input fluid and flow rate of fluid coming into the shell, temperature sensor range, valve capacity to increase the flow rate and pressure. The fuzzy-PID structure with multiplication operation is implemented as the controller. In addition to this the feed forward controller [12] is get involved for obtaining the benefits such as less peak overshoot and settling time has been obtained for the desired set point.

\section{MATHEMATICAL MODEL}

The temperature sensor is used in the system to get the feedback from the input fluid coming out from the heat exchanger. The sensor is designed in the range of sensing the temperature 500-1500C. The temperature signal is converted into the current signal by the transducer to the value of $4-20 \mathrm{~mA}$. The feedback gain and time constant is given as,

$$
K_{\text {feedback }}=\frac{(20-4) m A}{(150-50)^{0} \mathrm{C}}, T_{\text {feedback }}=10 \mathrm{sec}
$$

The transfer function of feedback is given by (1) and (2)

$$
G_{\text {feedback }}=\frac{1}{10 s+1} * 0.16
$$

The input fluid transfer function which is taken as disturbance model is given by,

$$
T_{\text {inputfluid }}=30 \text { sec, } G_{\text {inputfluid }}=\frac{1}{30 s+1} * \text { Varying input fluid gain }
$$

The transfer function of fluid flowing into the shell is given by,

$$
K_{\text {shellfluid }}=\frac{50^{0} c}{\left(\frac{k g}{s}\right)}, T_{\text {shellfluid }}=30 \mathrm{sec}, G_{\text {shellfluid }}=\frac{1}{30 s+1} * 50
$$

The measured sensor value which is converted into the current signal is again converted into pressure signal and it is calculated as.

$$
K_{\text {valve }}=\frac{(15-3) p s i}{(20-4) m A}
$$

The valve capacity gain is given by below equation, and the transfer function of the valve which is used to increase the flow rate of fluid coming into theshell is given by:

$$
K_{\text {valve capacity }}=\frac{1.6 \mathrm{~kg} / \mathrm{s}}{(15-6) p s i}, T_{\text {valve }}=3 \mathrm{sec}, G_{\text {valve }}=\frac{1}{3 s+1} * 0.75 * 0.13
$$

To control the temperature coming out of the tube outlet is controlled by the combined structure of fuzzy-PID controller as well as feed forward controller is also added in this part to diminishes the error caused by the input fluid disturbance coming through the tube inlet. The general block diagram in Figure 1 is included for easy understanding.

A fuzzy-PID controller in shell and tube heat exchanger simulation modeled for... (C. Somasundar Reddy) 


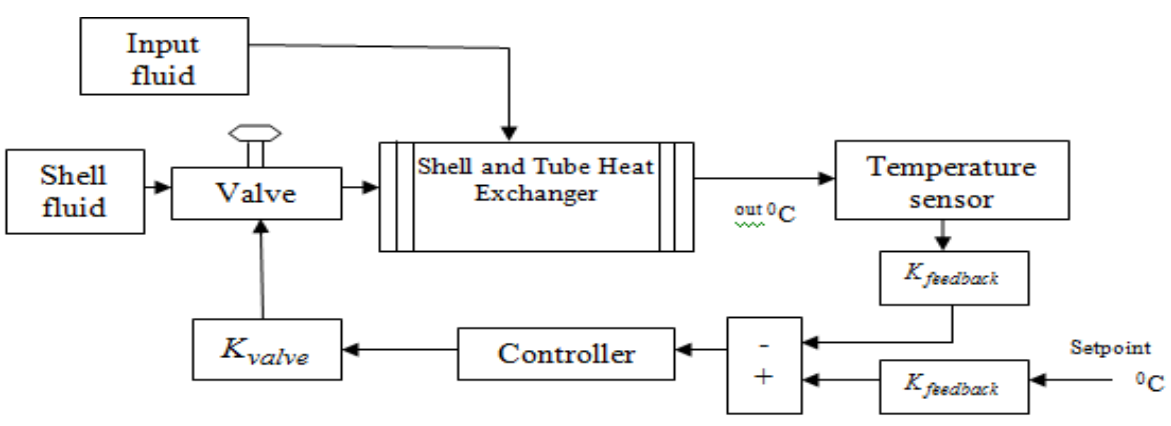

Figure 1. General block diagram

\section{CONTROLLERS}

\subsection{PID controller}

The PID controller is one of the most traditional controllers used in the control systems of the industry because of its simplicity and ease of implementation. Even though it has a simple structure the tuning of gain value makes some difficulties in using them. In general, PID consists of three signals such as proportional, integral and derivative signals and they are added each other to generate error correction signal to the plant model. The gains of each signal are a proportional gain $(\mathrm{Kd})$, integral gain $(\mathrm{Ki})$, derivative gain $(\mathrm{Kd})$. The input to the PID controller is error and output coming from the PID is error corrective value. The mathematical equation is given by:

$$
\text { PID output }=K_{p} * \text { error }+K_{i} * \int \text { error } * d t+K_{d} * \frac{d_{\text {error }}}{d t}
$$

There are several tuning methods are experimented for tuning the PID gains. In that Ziegler Nichols tuning has been used in this paper because of its fast\& adaptable gain process and non-complex structure [13]. ZieglerNicholas method consists of two types of tuning methodology,

- By finding the dead time and time constant

- By finding critical gain and critical time period

\subsubsection{First methodology}

In this method shown in Figure 2, the dead time (D) is calculated based on the time taken for the initial response of the set point. The time constant $(\mathrm{T})$ is found by the line drawn a tangent to the response curve up to the set point and subtracting the time corresponding to the tangent line meeting up the set point with the dead time. Kprocess is the gain of the process which is found by calculating the distance to meet the set point. This method of tuning is basically an open loop tuning method. The equations of the gain by the first methodology are given by:

$$
K_{p}=\frac{1.2 * T}{K_{\text {process }} * D}, K_{i}=2 * D, K_{d}=0.5 * D
$$

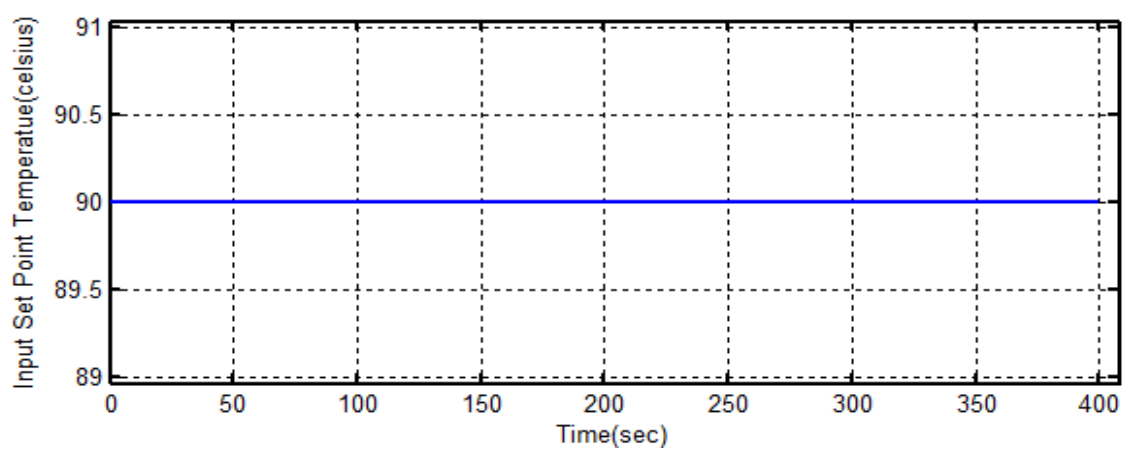

Figure 2. Input set point temperature 


\subsubsection{Second methodology}

In this method shown in Figure 3, the critical gain (Kcritical) and critical time period (Pcritical) is found by two methods. The first method is making the integral gain and derivative gain to zero and changing the proportional gain to find the point where the system becomes more unstable. The proportional gain with system becomes unstable with more number of oscillations is taken as critical gain (Kcritical). The critical time period (Pcritical) is found by calculating the time between those oscillations.

$$
K_{p}=0.6 * K_{\text {critical }}, K_{i}=0.5 * P_{\text {critical }}, K_{d}=0.125 * P_{\text {critical }}
$$

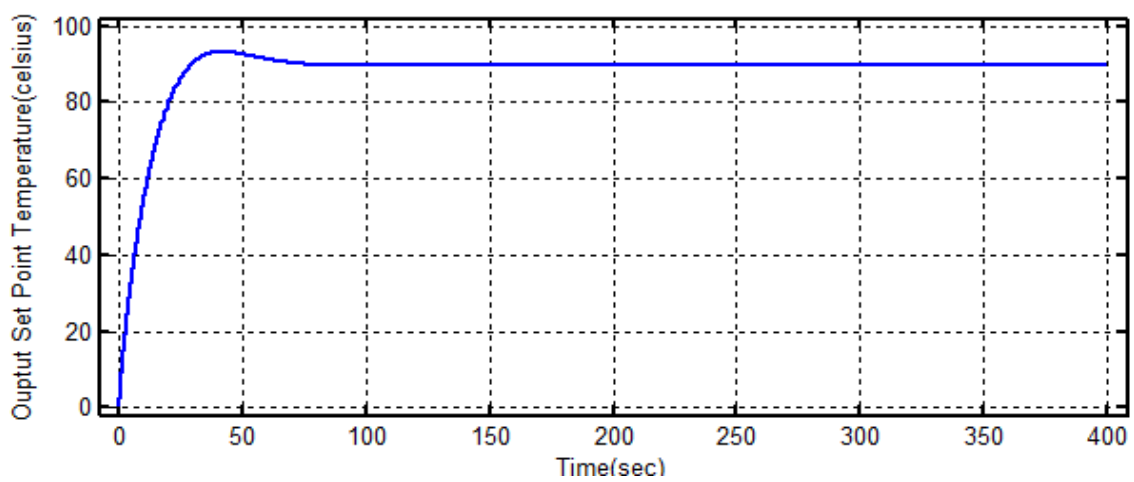

Figure 3. Output set point temperature

The second method includes the Routh criteria i.e., R-H criteria for finding the Kcritical and Pcritical. In this paper second methodology is implemented in which the first method is chosen and the Kp, $\mathrm{Ki}$ and $\mathrm{Kd}$ values are $13.25,0.36,56.25$ respectively.

\subsubsection{Feed Forward Controller}

The feed forward controller is also included in order to reduce the error caused by the input fluid which is treated as a disturbance. This controller rather than acting as a closed loop it will act as an open loop which reduces the complexity as well as a burden to the controller. The feed forward controller transfer function is given by:

$$
G_{\text {feedback }}=\frac{-18.461 s^{2}-6.769 s-0.205}{30 s^{2}+31 s+1}
$$

The above transfer function is obtained by the process transfer function and input fluid transfer function,

$$
G_{\text {process }}=\frac{4.875}{90 s^{2}+33 s+1}, G_{\text {feedback }}=\frac{G_{\text {inputfluid }}}{\left(G_{\text {process }}(s)\right)^{-1} *(\lambda s+1)}
$$

$\lambda$ ranges from 0 to 1 which is used as a parameter for filtering the transfer function to be accurate.

\subsection{Fuzzy controller}

The fuzzy controller system is introduced in many control application in industries to find the exact fittest points for the problem. Fuzzy used the fuzzy logic (FLC) system which is one of the combinations of human and expert knowledge system. The working of the expert system has a huge difference from normal Boolean expression. For example, the Boolean expression gives the answer whether the food is tasty or not tasty but the FLC gives the additional answer such as slightly tasty and slightly not tasty. With these results, we can find the exact solutions to the problems. The fuzzy system invokes the operation of converting the crisp values which are given as input to the fuzzy values by using the membership functions. The rules have been implemented based on the shell and tube heat exchanger model to get the fuzzy set output values [14]. The fuzzy set output values are converted into crisp outputs by using the defuzzification process. The rules of the proposed system are given in Table 1 
Table 1. Fuzzy set rules for the proposed model

\begin{tabular}{ccc}
\hline \multicolumn{3}{c}{ IF-THEN rules } \\
\hline$\Delta \mathrm{e}$ & $\mathrm{n}$ & $\mathrm{p}$ \\
$\mathrm{E}$ & & \\
$\mathrm{N}$ & $\mathrm{n}$ & $\mathrm{p}$ \\
$\mathrm{Ze}$ & $\mathrm{p}$ & $\mathrm{ze}$ \\
$\mathrm{P}$ & $\mathrm{ze}$ & $\mathrm{p}$ \\
\hline
\end{tabular}

\subsection{Fuzzy-PID}

The novel combination of fuzzy-PID is proposed in this paper for temperature control of shell and tube heat exchanger. There is various paper have been proposed in this combination [15]. The previously proposed methods are based on two types of operation. They are 1. Based on the logical operation 2. Based on the arithmetic operation. The fuzzy controller has to attain the dynamic response. The PI controller provides the response time interval and guarantees good steady-state response. Because of these advantages both the fuzzy and PI controllers are utilized.

\subsubsection{Based on the logical operation}

In this method, the Boolean operation is included for selecting which output has to be used for the plant model. There are two cases.

- The output is chosen based on comparing the outputs from the two controllers i.e., if the error signal is lower than the critical value then the input(i) is taken as false, value is given as 0 and if it is greater than input(i) is taken as true, value is given as 1 . The first case equation is given by:

$$
\text { Fuzzy }-P I D_{\text {out }}=\left(P I D_{\text {out }} \wedge \bar{\imath}\right) \vee\left(F u z z y_{\text {out }} \wedge i\right)
$$

In this case, the fuzzy output shows the high performance of steady state and PID output shows the high performance on the dynamic state.

- The second case also consists of the same operation but the equation varies and it is given by:

$$
\text { Fuzzy }-P I D_{\text {out }}=\left(P I D_{\text {out }} \wedge i\right) \vee\left(F u z z y_{\text {out }} \wedge \bar{l}\right)
$$

In this case, the fuzzy output and PID output is contradicted when compared to the first case i.e., fuzzy shows the high performance of dynamic state and PID output shows the high performance on steady state.

\subsubsection{Based on the arithmetic operation}

In this method, the arithmetic operation is utilized for getting the output which is given to the plant model. It also consists of two cases.

- This case uses the addition operation includes the adding of the output coming from the fuzzy and PID.

The addition operation invokes the setting the saturation limit to the overflow. The equation is :

$$
\text { Fuzzy }-P I D_{\text {out }}=P I D_{\text {out }}+\text { Fuzzy } y_{\text {out }}
$$

This combination fuzzy-PID includes both the advantages and disadvantages of the individual controller to the plant model.

- This case used the multiplication operation includes the multiplying of the output coming from the fuzzy and PID. This multiplication operation performs the amplifier action which saturates the overflow. The fuzzy amplifies the output coming from the PID and the amplified signal is given to the plant model. The equation is given by:

$$
\text { Fuzzy }-P I D_{\text {out }}=P I D_{\text {out }} * \text { Fuzzy } y_{\text {out }}
$$

In this paper, the fuzzy-PID with multiplication operation is implemented because of the less overshoot and settling time than the addition operation based fuzzy-PID. The proposed controller block diagram is shown in Figure 4. 


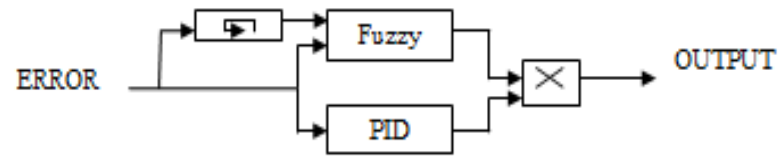

Figure 4. Proposed controller block diagram

\section{RESULTS AND ANALYSIS}

Simulation testing shown in Figure 5 has been done on the transfer function modeled shell and tube heat exchanger. The simulation run time is chosen as 400sec and the set point temperature is kept at 900C, input fluid gain is kept as 20 and $\mathrm{Kp}, \mathrm{Ki}, \mathrm{Kd}$ values are kept as 13.25, 0.36, 56.25 respectively and the results have been obtained for the verification with conventional one using MATLAB/SIMULINK. Figures 2 and 3 shows the input and output set point temperature. Fuzzy-PID controller output, Fuzzy-PID+Feed forward controller output are shown in Figures 6 and 7 respectively. The settling time and peak overshoot shown in Figures 8 and 9 has been compared with conventional method. The settling time of conventional method is $81.6 \mathrm{sec}$. The settling time of set point temperature using proposed controller is $74 \mathrm{sec}$. The conventional peak overshoot is $5.4 \%$ but in proposed peak overshoot of set point temperature is $3.54 \%$.

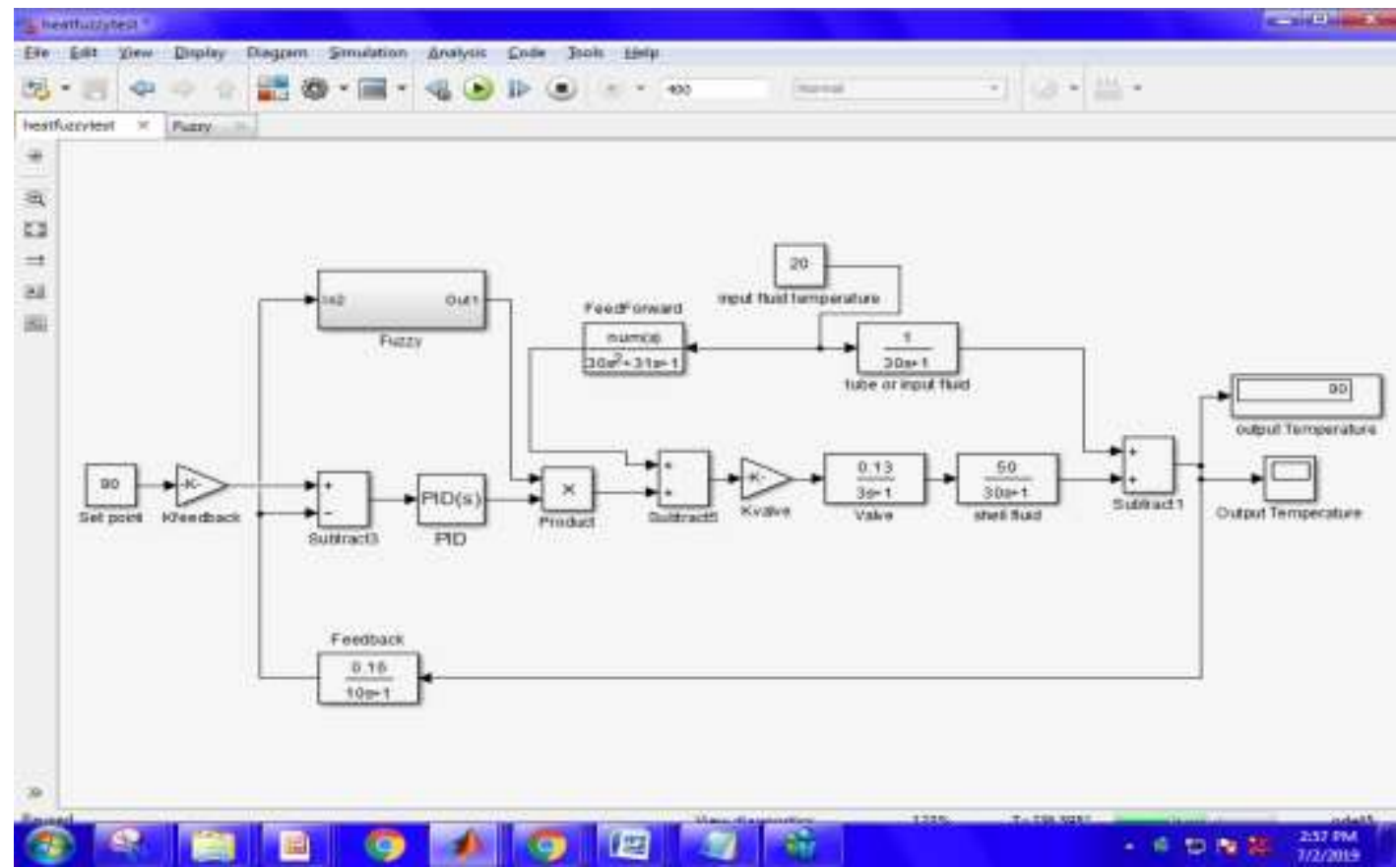

Figure 5. Simulation test model

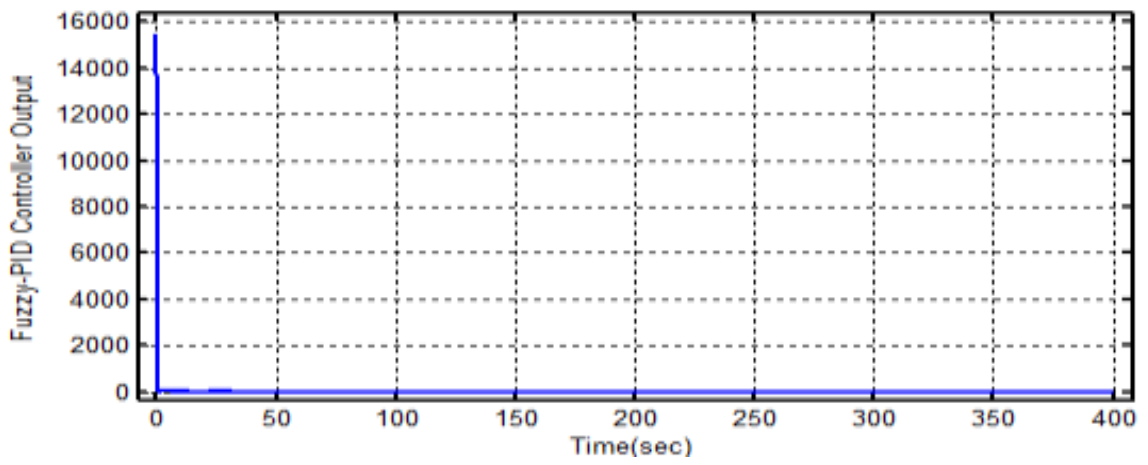

Figure 6. Fuzzy-PID controller output 


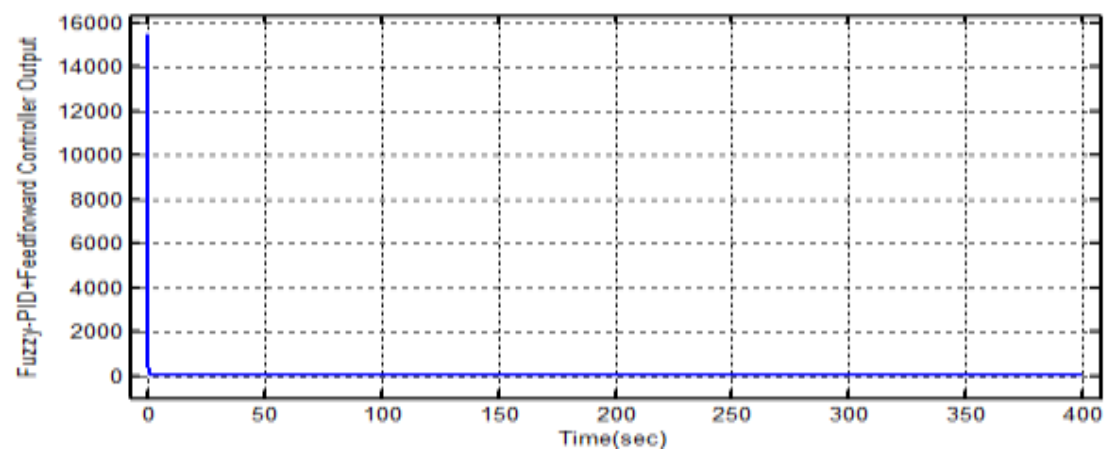

Figure 7. Fuzzy-PID+Feedforward controller output

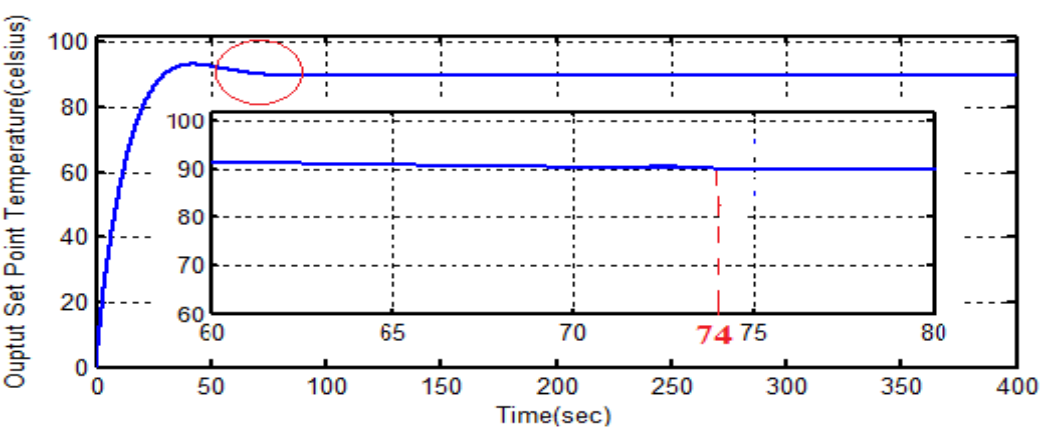

Figure 8. Settling time of set point temperature using proposed controller

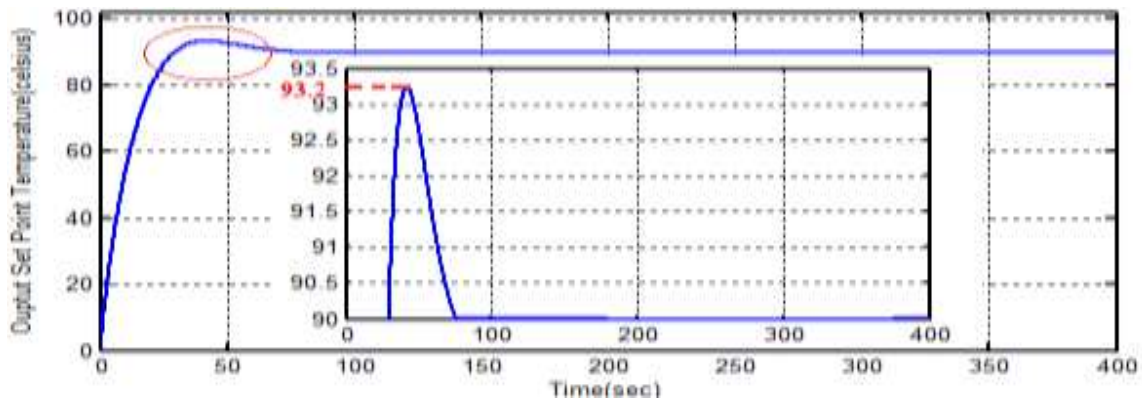

Figure 9. Peak Overshoot of set point temperature using proposed controller

The peak overshoot percentage is calculated as:

$$
\% \text { peakovershoot }=\frac{93.2-90}{90} * 100=3.54 \%
$$

\section{CONCLUSION}

Simulation has been done on the temperature control on the shell and tube heat exchanger model using fuzzy-PID controller. The shell and tube heat exchanger controller part is modeled by the transfer function model. The fuzzy-PID with feed forward controller is implemented to reduce the error caused by the input fluid. The PID tuning is done by the Ziegler-Nicholas method which is one of the fast\& adaptable gain process and non-complex structure tuning methods. The fuzzy has been modeled based on the shell and tube heat exchanger model which acts as an amplifier for the PID output. The fuzzy-PID which is the combined using multiplication operation has made peak overshoot and settling time of output set point temperature with the least values of $3.54 \%$ and $74 \mathrm{sec}$ respectively. The values of peak overshoot and settling time obtained from the proposed control strategy which is less than the PI control method. 


\section{REFERENCES}

[1] S. M. Jafari, F. Saramnejad and D.Dehnad, "Designing and application of a shell and tube heat exchanger for nanofluid thermal processing of liquid food products," Journal of food process engineering, vol. 41, no. 3, pp.1-10. 2018.doi: https://doi.org/10.1111/jfpe. 12658

[2] L. Costiuc and V. Popa, "Simulink Model for a Heat-Exchanger, " [Onlline]. Accesed: http://aspeckt.unitbv.ro/jspui/bitstream/123456789/1209/1/859.pdf

[3] S. Nithya, N. Sivakumaran, T. Balasubramanian and N. Anantharaman, "Model based controller design for a spherical tank process in real time," IJSSST, vol. 9, no. 4, pp.25-31, 2008. http://ijssst.info/Vol-09/No-4/paper4.pdf

[4] S. Gupta, R. Gupta and S. Padhee, "Parametric system identification and robust controller design for liquid-liquid heat exchanger system," IET Control Theory \& Applications, vol. 12, no. 10, pp.1474-1482.doi: 10.1049/iet-cta.2017.1128, 2018.

[5] N.Sarah, et al,"Speed control of DC motor using conventional and adaptive PID controllers," Indonesian Journal of Electrical Engineering and Computer Science, vol. 16, no. 3, pp. 1221-1228, 2019.

[6] M. K. Thufail and K. Balaji, "Analysis and improvement of self tuning based on sensor less control of BLDC motor," Indian Journal of Public Health Research \& Development, vol. 8, no. 3, pp.623-629, 2017. doi: 10.5958/0976-5506.2017.00296.0

[7] K. J. Åström and T. Hägglund, "Revisiting the Ziegler-Nichols step response method for PID control," Journal of process control, vol. 14, no. 6, pp.635-650, 2004. https://doi.org/10.1016/j.jprocont.2004.01.002

[8] Hasmah Mansor, Tun Mohamad Aqil Mohamad Fadzir, Teddy Surya Gunawan, Zuriati Janin, "Design of travel angle control of quanser bench-top helicopter using mamdani-based fuzzy logic controller," Indonesian Journal of Electrical Engineering and Computer Science, vol. 17, no. 2, pp. 815-825, 2020.

[9] Li, Han-Xiong, Lei Zhang, Kai-Yuan Cai, and Guanrong Chen. "An improved robust fuzzy-PID controller with optimal fuzzy reasoning," IEEE Transactions on Systems, Man, and Cybernetics, Part B (Cybernetics) 35, no. 6 2005, pp. 1283-1294.

[10] Somwanshi, D., Bundele, M., Kumar, G. and Parashar, G., 2019, "Comparison of fuzzy-PID and PID controller for speed control of DC motor using LabVIEW,” Procedia Computer Science, 152, pp.252-260.

[11] Saruchi, S.A., et al, "Novel motion sickness minimization control via fuzzy-PID controller for autonomous vehicle," Applied Sciences, vol. 10, no.14, pp.4769, 2020.

[12] A. Kumar and K. Balaji, "PI and sliding mode speed control of permanent magnet synchronous motor fed from three phase four switch VSI," Journal of Mechanical Engineering Research and Developments, vol. 40, pp.716725.doi: 10.7508/jmerd.2017.04.019, 2017.

[13] Nimawat, D. and Nagar, N., "Self-tuning fuzzy PID controllers application on industrial hydraulic actuator using unique system identification approach," Journal of Communications Technology, Electronics and Computer Science, vol. 22, pp.1-6, 2019.

[14] G.V. Kumar, "Fuzzy-PID control method of hybrid derived boost converter (HDBC) using wind energy," International Journal of MC Square Scientific Research, vol. 9, no.1, pp.1-10, 2018.

[15] N. Manie and B. Pattanaik, "Zeta DC-DC converter based on MPPT Technique for BLDC Application,"International Journal of MC Square Scientific Research, vol. 11, no.2, pp.1-12, 2019.

[16] M. I. Berto and V. Silveira JR, "Configuration of PID/Feed back and PID/feed back/feed forward controllers in temperature control of a HTST heat exchanger," In 2thMer-cosur Congress on Chemical Engineering and 4thMercosur Congress on Process SystemsEngineering, 2004. [Online]. Accesed: https://pdfs.semanticscholar.org/07ed/59ed5ab04b01ca9541e34a02c6b96512dc23.pdf

[17] P.M. Meshram and R.G. Kanojiya, "Tuning of PID controller using Ziegler-Nichols method for speed control of DC motor," In IEEE-international conference on advances in engineering, science and management (ICAESM2012), pp. 117-122, 2012.

[18] Debnath, M.K., Jena, T. and Sanyal, S.K.,"Frequency control analysis with PID-fuzzy-PID hybrid controller tuned by modified GWO technique," International Transactions on Electrical Energy Systems, vol. 29, no.10, p.e12074, 2019.

[19] Gheisarnejad, M., "An effective hybrid harmony search and cuckoo optimization algorithm based fuzzy PID controller for load frequency control," Applied Soft Computing, vol. 65, pp.121-138, 2018.

[20] Pandey, Mridul, K. Ramkumar and V. Alagesan, "Design of fuzzy logic controller for a cross flow shell and tube heat-exchanger," In IEEE-International Conference on Advances in Engineering, Science and Management (ICAESM-2012), pp. 150-154,2012.

[21] Wang, Y., Jin, Q. and Zhang, R., "Improved fuzzy PID controller design using predictive functional control structure," ISA transactions, 71, pp.354-363, 2017.

[22] Nayak, N., Mishra, S., Sharma, D. and Sahu, B.K., "Application of modified sine cosine algorithm to optimally design PID/fuzzy-PID controllers to deal with AGC issues in deregulated power system," IET Generation, Transmission \& Distribution, vol. 13, no. 12, pp.2474-2487, 2019.

[23] Mahto, T. and Mukherjee, V., "Fractional order fuzzy PID controller for wind energy-based hybrid power system using quasi-oppositional harmony search algorithm," IET Generation, Transmission \& Distribution, vol.11, no. 13, pp.3299-3309, 2017.

[24] Mohanty, P.K., et al., "Design and analysis of fuzzy PID controller with derivative filter for AGC in multi-area interconnected power system," IET Generation, Transmission \& Distribution, vol. 10, no.15, pp.3764-3776, 2016.

[25] N. C. Damasceno and O. Gabriel Filho, "PI controller optimization for a heat exchanger through metaheuristic Bat algorithm, particle swarm optimization, flower pollination algorithm and Cuckoo search algorithm," IEEE Latin America Transactions, vol. 15, no. 9, pp.1801-1807, 2017. doi: 10.1109/TLA.2017.8015088 